\title{
Changes in Cyclooxygenase-2 Immunoreactivity in the Hippocampus in a Model of Streptozotocin-Induced Type 1 Diabetic Rats
}

\author{
Sung Min NAM ${ }^{1)}$, Sun Shin $\mathrm{YI}^{2)}$, Dae Young YOO ${ }^{1)}$, Woosuk KIM ${ }^{1)}$, Jung Hoon $\mathrm{CHOI}^{3)}$, In Koo HWANG ${ }^{1)}$, Je Kyung \\ $\mathrm{SEONG}^{1)}$ and Yeo Sung YOON ${ }^{1) *}$ \\ 1) Department of Anatomy and Cell Biology, College of Veterinary Medicine, and Research Institute for Veterinary Science, Seoul \\ National University, Seoul 151-742, South Korea \\ ${ }^{2)}$ Department of Biomedical Laboratory Science, College of Medical Sciences, Soonchunhyang University, Asan 336-745, South Korea \\ ${ }^{3)}$ Department of Anatomy, College of Veterinary Medicine, Kangwon National University, Chuncheon 200-701, South Korea
}

(Received 29 January 2012/Accepted 7 March 2012/Published online in J-STAGE 21 March 2012)

ABSTRACT. In this study, we investigated diabetic stage dependent cyclooxygenase-2 (COX-2) immunoreactivity in the dentate gyrus in streptozotocin (STZ)-induced type 1 diabetic rats. The animals were sacrificed at 2, 3 and 4 weeks after STZ treatment. Blood glucose levels were increased after STZ treatment. COX-2 immunoreactivity in dentate gyrus was significantly increased in these regions 3 weeks after STZ treatment and restored to its basal level to 4 weeks after STZ treatment. In contrast, COX-2 immunoreactivity was not changed in CA3 region in all groups. These results suggest that STZ-induced type 1 diabetes transiently, but not permanently, decreased synaptic transmission and plasticity 3 weeks after STZ treatment in the dentate gyrus.

KEY WORDS: cyclooxygenase-2, hippocampus, streptozotocin, type 1 diabetes.

doi: 10.1292/jvms.12-0036; J. Vet. Med. Sci. 74(8): 977-982, 2012

Commonly, there are two types of diabetes mellitus (DM); type 1 DM shows massive loss of pancreatic $\beta$ cells causing absolute insulin deficiency, while type 2 DM demonstrates relative insulin deficiency in addition to insulin resistance triggered by hyperglycemia which is the key to diabetic clinical symptoms [15]. In brain, neuronal insulin signaling plays an important role in synaptic formation and regeneration of neurons in brain [4] and decreased levels or sensitivity is related with type 1 or $2 \mathrm{DM}$, respectively. Diabetes impairs the neuronal adaptive ability to oxidative and metabolic stress [16], and alters hippocampal neurogenesis and neuropathy in dorsal root ganglion $[12,27]$. Durationdependent differences like hippocampal neuronal apoptosis are reported [21].

For an animal model of type $1 \mathrm{DM}$, we selected the streptozotocin (STZ) treated rat. STZ interacts with $\beta$-cell selectivity via the glucose transporter 2 [20]. Its toxicity is induced by DNA alkylating activity of its methylnitrosourea moiety, poly-ADP-ribose polymerase overstimulation, and cellular energy depletion [20]. In many studies including ours, STZ-induced animal models are used for studying the effects of type 1 diabetes mellitus [5, 18, 32].

Cyclooxygenase (COX), a membrane-bound protein, is involved in inflammation, angiogenesis, colon cancer and Alzheimer's disease [8, 11], and classified into two types, COX-1 and COX-2. Both isoenzymes convert arachidonic acid into multifunctional prostanoids. COX-2 enzyme is

*Correspondence to: Yoon, Y. S., Department of Anatomy and Cell Biology, College of Veterinary Medicine, Seoul National University, Seoul 151-742, South Korea.

e-mail: ysyoon@snu.ac.kr

(C)2012 The Japanese Society of Veterinary Science reported as a key player [11] in neuro-inflammation which is involved in most neurodegenerative disorders by eliciting neuronal death and influencing formation of new neurons [9]. In several tissues, mRNA level of COX-2 was studied and level in the brain was lowest [24], but its expression in brain was not the lowest [35]. In brain, COX-2 is involved in normal neuronal function and expressed constitutively at high levels in neurons of the hippocampus, cortex and amygdala, and lower levels in the caudate putamen, thalamus and hypothalamus [34]. Also, the function of COX-2 includes memory consolidation, acquisition and retrieval $[26,29,31]$.

In our previous studies, we observed that the expression of COX-2 and hippocampal neurogenesis is closely associated in a type 2 DM model, the Zucker diabetic fatty rat [13]. However, there are no comparative studies on the expression of COX-2 in the type 1 diabetic animals. In the present study, therefore, we investigated changes in COX-2 immunoreactivity in the hippocampus of STZ-induced type 1 diabetic animals.

\section{MATERIALS AND METHODS}

Experimental animals: Seven-week-old male Wistar rats were purchased from Orient Bio, Inc. (Seongnam, South Korea). The animals were housed in a conventional state under adequate temperature $\left(23^{\circ} \mathrm{C}\right)$ and humidity $(60 \%)$ control with a 12-hr light/12-hr dark cycle, and were given ad libitum access to water and food. The procedures for handling and caring of animals follow the Guide for the Care and Use of Laboratory Animals issued by Institute of Laboratory Animal Resources, U.S.A., 1996, and the experimental protocol was approved by the Institutional Animal Care 
and Use Committee (IACUC) of Seoul National University (approval no. SNU-080128-6). All of the experiments were conducted to minimize the number of animals used and the suffering caused by the procedures used in the present study.

Induction of type $1 \mathrm{DM}$ and experimental design: STZ (Sigma-Aldrich, St. Louis, MO, U.S.A.) was dissolved in a $0.1 \mathrm{M}$ sodium citrate buffer ( $\mathrm{pH}$ 4.3). Following one week acclimation to the vivarium, diabetes was induced by a single intraperitoneal injection of $75 \mathrm{mg} / \mathrm{kg}$ of STZ. For the control group, sodium citrate buffer was treated intraperitoneally as the same volume in STZ. After $72 \mathrm{hr}$, fasting blood glucose levels were monitored and rats with blood glucose levels of $>8.0 \mathrm{mmol} / l$ were utilized for the study and divided into 4 groups.

Check for blood glucose levels: Blood was sampled by a "tail nick" at 9-11 a.m. using a $27 \mathrm{G}$ needle before sacrifice and glucose in blood from a non-fasting state was analyzed by using a blood glucose monitor (SureStep ${ }^{\mathrm{TM}}$ blood glucose meter, Lifescan, CA, U.S.A.).

Tissue processing: For immunohistochemical analysis, vehicle- and STZ-treated rats at 2, 3 and 4 weeks after STZ treatment ( $\mathrm{n}=5$ per group) were anesthetized with $30 \mathrm{mg} / \mathrm{kg}$ Zoletil 50 (Virbac, Carros, France) and perfused with $0.1 \mathrm{M}$ phosphate-buffered saline (PBS, pH 7.4) followed by $4 \%$ paraformaldehyde in $0.1 \mathrm{M}$ phosphate-buffer ( $\mathrm{PB}, \mathrm{pH}$ 7.4). The brains were removed and postfixed in the same fixative for $6 \mathrm{hr}$. The brain tissues were cryoprotected by infiltration with $30 \%$ sucrose overnight. The $30-\mu \mathrm{m}$-thick brain sections in coronal plane were serially cut using a cryostat (Leica, Wetzlar, Germany). The sections were collected into sixwell plates containing PBS for further processing.

Immunohistochemistry for COX-2: To obtain accurate data for immunohistochemistry, the free-floating sections were carefully processed under the same conditions. The tissue sections were selected between $-3.00 \sim-4.08 \mathrm{~mm}$ to the bregma in reference to a rat atlas [25] for each animal. The sections were sequentially treated with $0.3 \%$ hydrogen peroxide $\left(\mathrm{H}_{2} \mathrm{O}_{2}\right)$ in PBS for 30 min and $10 \%$ normal goat serum in $0.05 \mathrm{M}$ PBS for $30 \mathrm{~min}$. They were then incubated with diluted rabbit anti-COX-2 (1:200, Cayman, Ann Arbor, MI, U.S.A.) overnight at room temperature and subsequently exposed to biotinylated goat anti-rabbit IgG and streptavidin peroxidase complex $(1: 200$, Vector, Burlingame, CA, U.S.A.). They were then visualized by reaction with 3,3'-diaminobenzidine tetrachloride (Sigma, St. Louis, MO, U.S.A.) in $0.1 \mathrm{M}$ Tris- $\mathrm{HCl}$ buffer (pH 7.2) and mounted on gelatin-coated slides. The sections were mounted in Canada Balsam (Kanto, Tokyo, Japan) following dehydration.

Analysis of a region of interest in the hippocampus was performed using an image analysis system. Images were calibrated into an array of $512 \times 512$ pixels corresponding to a tissue area of $140 \times 140 \mu \mathrm{m}$ (40× primary magnification). Each pixel resolution was 256 gray levels. The intensity of COX-2 immunoreactivity was evaluated by means of a relative optical density (ROD), which was obtained after the transformation of the mean gray level using the formula: $\mathrm{ROD}=\log (256 /$ mean gray level). ROD of background was determined in unlabeled portions and the value subtracted

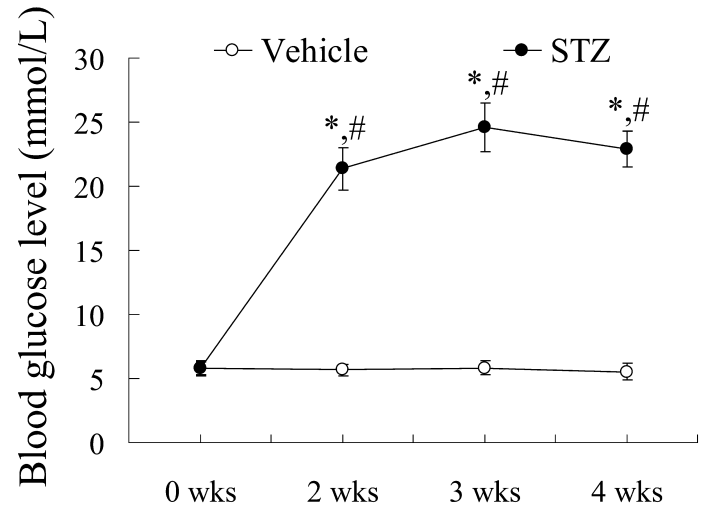

Fig. 1. Changes in blood glucose levels at 0, 2, 3 and 4 weeks after vehicle or STZ treatment. Differences among the means were analyzed statistically by two-way analysis of variance followed by Duncan's new multiple range method ( $\mathrm{n}=5$ per group; $* P<0.05$, significantly different from vehicle-treated group, $\# P<0.05$, significantly different from the 0 week post-treatment group). The bars indicate SE.

for correction, yielding high ROD values in the presence of preserved structures and low values after structural loss using NIH Image 1.59 software. A ratio of the ROD was calibrated as $\%$.

Statistical analysis: The data shown here represent the means of experiments performed for each experimental area. Differences among the means were statistically analyzed by two-way analysis of variance followed by Duncan's posthoc analysis in order to elucidate differences.

\section{RESULTS}

Changes in blood glucose levels: In the pre-diabetic stages, the blood glucose levels were similar between vehicle- and STZ-treated groups (5.81 and $5.83 \mathrm{mmol} / l$, respectively). In the vehicle-treated group, the blood glucose level did not change significantly 4 weeks after vehicle treatment. However, in the STZ-treated group, blood glucose level significantly increased at 2 weeks after STZ treatment compared to the vehicle-treated counterpart and higher blood glucose levels were maintained 4 weeks after STZ treatment. At 3 weeks after STZ treatment, the blood glucose peaked and slightly decreased 4 weeks after STZ treatment (Fig. 1).

Changes in COX-2 immunoreactivity: COX-2 immunoreactivity was mainly detected in the granule cells and some interneurons in polymorphic layer of dentate gyrus in all groups (Fig. 2). However, there were significant differences in COX-2 immunoreactivity in dentate gyrus between groups. In the vehicle-treated groups, there were no significant changes with time after treatment (data not shown). At 4 weeks after vehicle treatment, COX-2 immunoreactivity was detected mainly in the granule cell layer of the dentate gyrus (Fig. 2A). At 2 weeks after STZ treatment, COX-2 immunoreactivity was slightly increased in the dentate gyrus 

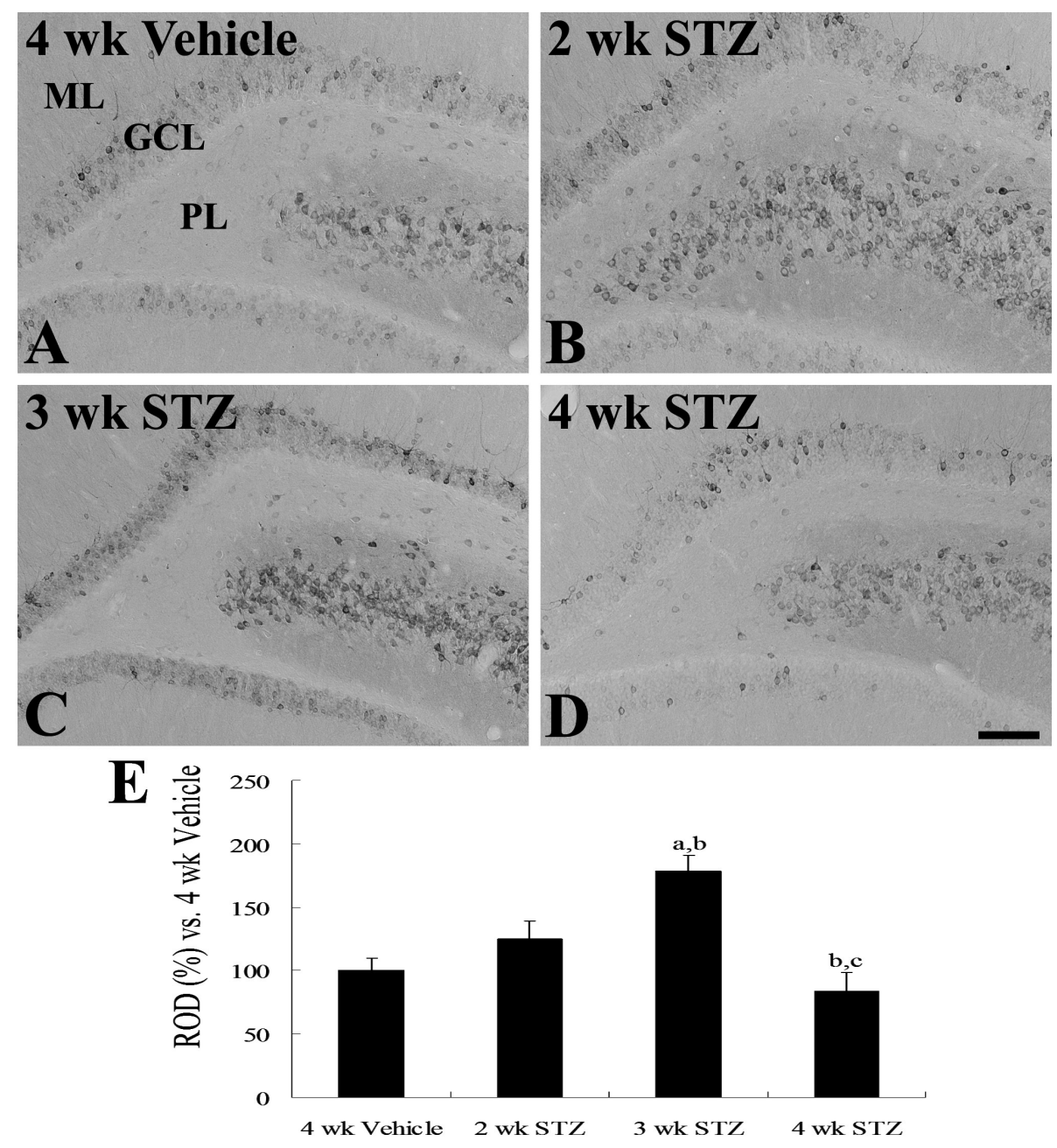

Fig. 2. Cyclooxygenase-2 (COX-2) immunoreactivity in the dentate gyrus of groups at 4 weeks after vehicle treatment (A), and 2 (B), 3 (C) or 4 weeks (D) after STZ treatment. COX-2 immunoreactivity is found in the granule cell layer (GCL) of the dentate gyrus. PL, polymorphic layer; ML, molecular layer. Scale bar $=100 \mu \mathrm{m}$. E: Relative optical densities (ROD) as percentage values of COX-2 in the dentate gyrus of rats groups at 4 weeks after vehicle treatment, and 2, 3 or 4 weeks after STZ treatment. Differences among the means were analyzed statistically by one-way analysis of variance followed by Newman-Keuls method ( $\mathrm{n}=5$ per group; a $P<0.05$, significantly different from vehicletreated group, b $P<0.05$, significantly different from the 2 weeks post-treatment group; c $P<0.05$, significantly different from the 3 weeks post-treatment group). The bars indicate the SEM.

compared to that in the control group (Fig. 2B and 2E). At 3 weeks after STZ treatment, COX-2 immunoreactivity was significantly increased in the dentate gyrus compared to the control or 2 weeks post-STZ group (Fig. 2C and 2E). At 4 weeks after STZ treatment, COX-2 immunoreactivity was significantly decreased in the dentate gyrus compared to that in the 2 or 3 weeks post-STZ group and slightly low compared to that in the control group (Fig. 2D and 2E).

COX-2 immunoreactivity was mainly detected in the stratum pyramidale of CA3 region (Fig. 3). However, there were no significant differences in COX-2 immunoreactivity in $\mathrm{CA} 3$ region between groups (Fig. 3).

\section{DISCUSSION}

Diabetic brain shows cognitive deficits and increased risk of developing dementia, especially the incidence of Alzheimer's disease [18]. In a previous study, the MRI differences in brain lesions between the two type diabetes were compared and more prominent cognitive disturbances were found in type 2 DM [3]. In particular, hippocampus-based memory impairments and cognitive dysfunction are reported in both type of DM $[1,10]$. In non-obese, type $1 \mathrm{DM}$ mice, reduction of hippocampal neurogenesis is reported [2] and in our previous report with STZ-induced type $1 \mathrm{DM}$ rats, that pattern was also observed [5]. 

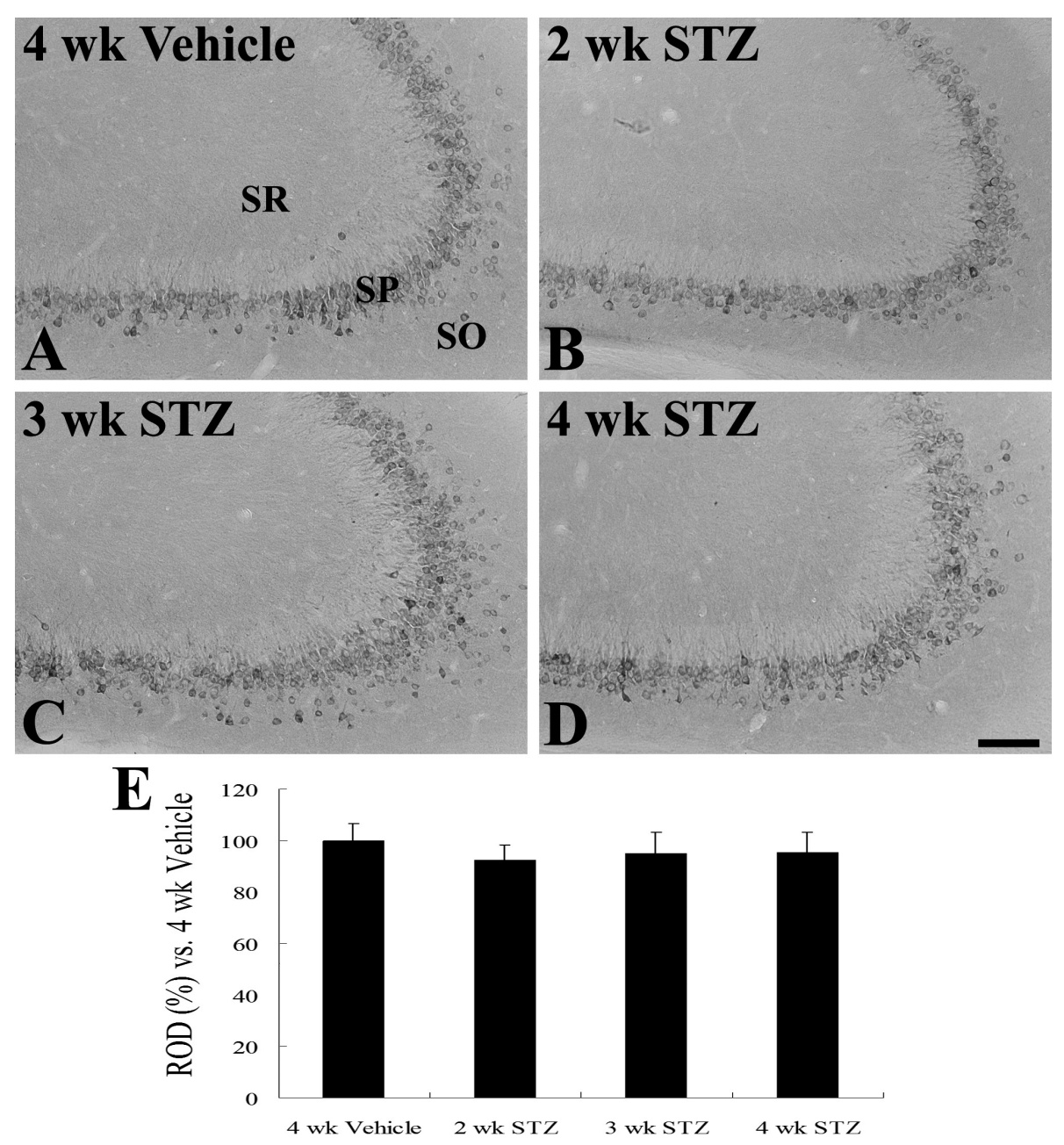

Fig. 3. Cyclooxygenase-2 (COX-2) immunoreactivity in the hippocampal CA3 region of groups at 4 weeks after vehicle treatment (A), and 2 (B), 3 (C) or 4 weeks (D) after STZ treatment. COX-2 immunoreactivity is found in the stratum pyramidale (SP) of the CA3 region. SO, stratum oriens; SR, stratum pyramidale. Scale bar $=100 \mu \mathrm{m}$. E: Relative optical densities (ROD) as percentage values of COX-2 in the CA3 region of rats groups at 4 weeks after vehicle treatment, and 2, 3 or 4 weeks after STZ treatment. Differences among the means were analyzed statistically by one-way analysis of variance followed by Newman-Keuls method. There are no significant differences between groups. The bars indicate the SEM.

In this study, we investigated COX-2 immunoreactivity in the dentate gyrus and hippocampal $\mathrm{CA} 3$ region in diabetic rats. There were some differences in expression of COX-2 between vehicle-treated control and STZ-treated diabetic animals. COX-2 immunoreactivity was significantly increased in the dentate gyrus, not CA3 region, after STZ treatment, but after this period, the increase pattern was conversed.

The changes of COX-2 immunoreactivity in the dentate gyrus, not CA3 region may be associated with the neurogenesis occurred in the dentate gyrus. COX-2's action is involved with various prostaglandins [28], cell cycle proteins [23] and the NMDA receptor [19]. Still, COX-2's roles in neurogenesis are not fully elucidated and it can behave like a double-edged sword with positive or negative effect. One of possible actions of COX-2 is on cell cycle proteins. COX-2 showed a positive effect on proliferation of neural progenitor cells and synaptic plasticity [28]. COX-2 inhibition is related with memory impairment and COX-2 knockouts showed reduced hippocampal neurogenesis [31]. In our previous study, we reported that STZ significantly increased latency time in a Morris water maze test and doublecortin immunoreactive neuroblasts were significantly decreased 2-3 weeks after STZ treatment [5]. However, in the present study, we observed the decrease of COX-2 immunoreactivity in the dentate gyrus at 4 weeks after STZ treatment. This result was coincided with previous study that doublecortin immunoreactive neuroblasts were increased at 4 weeks after STZ treatment [5]. It has been reported that neurogenesis is 
transiently increased in brain damage such as ischemia [6, $14,30,33]$. In type 2 diabetic rats, we reported that diabetes significantly reduced cell proliferation, neuroblast differentiation and COX-2 levels in the dentate gyrus [12, 13]. In addition, the blockade of COX-2 by celecoxib significantly ameliorated the reduction of neuroblast differentiation [13]. Our results strongly suggest that the action of COX-2 is related to neuroblast differentiation in the dentate gyrus.

Another possible action of COX-2 is the pro-inflammatory effect. In STZ-induced diabetic animals, insulin treatment resulted in reduced ischemia and reperfusion injury with decreased expression of nuclear factor- $\kappa \mathrm{B}, \mathrm{COX}-2$ and inducible nitric oxide synthase [7]. In alcohol-induced brain damage, COX-2 was induced and its pattern was similar to that induced by excitatory amino acids [19], and COX-2 induction was also observed after seizure in rats [34]. Increased expression of COX-2 is reported to be related with reactive oxygen species and neuronal oxidative stress [22]. Alteration of the COX-2 pathway and oxidative stress was reported to being related with diabetic neuropathy [17]. In the present study, we also observed transient increase of COX-2 immunoreactivity in the dentate gyrus.

In conclusion, after STZ treatment, a type 1 diabetic-like state was induced in rats and COX-2 immunoreactivity was transiently increased in the dentate gyrus, not hippocampal CA3 region, 2-3 weeks after STZ treatment. These increases of COX-2 immunoreactivity may be associated with reduction of neural plasticity in the dentate gyrus.

ACKNOWLEDGMENT. This work was supported by a National Research Foundation of Korea Grant funded by the Korean Government (MEST), Republic of Korea (20100007712).

\section{REFERENCES}

1. Alvarez, E. O., Beauquis, J., Revsin, Y., Banzan, A. M., Roig, P., de Nicola, A. F. and Saravia, F. 2009. Cognitive dysfunction and hippocampal changes in experimental type 1 diabetes. Behav. Brain Res. 198: 224-230. [Medline] [CrossRef]

2. Beauquis, J., Saravia, F., Coulaud, J., Roig, P., Dardenne, M., Homo-Delarche, F. and de Nicola, A. 2008. Prominently decreased hippocampal neurogenesis in a spontaneous model of type 1 diabetes, the nonobese diabetic mouse. Exp. Neurol. 210: 359-367. [Medline] [CrossRef]

3. Brands, A. M., Biessels, G. J., Kappelle, L. J., de Haan, E. H., de Valk, H. W., Algra, A. and Kessels, R. P. 2007. Cognitive functioning and brain MRI in patients with type 1 and type 2 diabetes mellitus: a comparative study. Dement. Geriatr. Cogn. Disord. 23: 343-350. [Medline] [CrossRef]

4. Chiu, S. L., Chen, C. M. and Cline, H. T. 2008. Insulin receptor signaling regulates synapse number, dendritic plasticity, and circuit function in vivo. Neuron 58: 708-719. [Medline] [CrossRef]

5. Choi, J. H., Hwang, I. K., Yi, S. S., Yoo, K. Y., Lee, C. H., Shin, H. C., Yoon, Y. S. and Won, M. H. 2009. Effects of streptozotocin-induced type 1 diabetes on cell proliferation and neuronal differentiation in the dentate gyrus; correlation with memory impairment. Korean J. Anat. 42: 41-48.

6. Choi, J. H., Yoo, K. Y., Lee, C. H., Park, J. H., Yan, B. C., Kwon,
S. H., Seo, J. Y., Cho, J. H., Hwang, I. K. and Won, M. H. 2012. Comparison of neurogenesis in the dentate gyrus between the adult and aged gerbil following transient global cerebral ischemia. Neurochem. Res. (in press). [Medline] [CrossRef]

7. Collino, M., Aragno, M., Castiglia, S., Tomasinelli, C., Thiemermann, C., Boccuzzi, G. and Fantozzi, R. 2009. Insulin reduces cerebral ischemia/reperfusion injury in the hippocampus of diabetic rats. Diabetes 58: 235-242. [Medline] [CrossRef]

8. Dannhardt, G. and Kiefer, W. 2001. Cyclooxygenase inhibitors - current status and future prospects. Eur. J. Med. Chem. 36: 109-126. [Medline] [CrossRef]

9. Das, S. and Basu, A. 2008. Inflammation: a new candidate in modulating adult neurogenesis. J. Neurosci. Res. 86: 1199-1208. [Medline] [CrossRef]

10. Gold, S. M., Dziobek, I., Sweat, V., Tirsi, A., Rogers, K., Bruehl, H., Tsui, W., Richardson, S., Javier, E. and Convit, A. 2007. Hippocampal damage and memory impairments as possible early brain complications of type 2 diabetes. Diabetologia 50: 711-719. [Medline] [CrossRef]

11. Hoozemans, J. J., Rozemuller, J. M., van Haastert, E. S., Veerhuis, R. and Eikelenboom, P. 2008. Cyclooxygenase-1 and -2 in the different stages of Alzheimer's disease pathology. Curr. Pharm. Des. 14: 1419-1427. [Medline] [CrossRef]

12. Hwang, I. K., Yi, S. S., Song, W., Won, M. H., Yoon, Y. S. and Seong, J. K. 2010. Effects of age and treadmill exercise in chronic diabetic stages on neuroblast differentiation in a rat model of type 2 diabetes. Brain Res. 1341: 63-71. [Medline] [CrossRef]

13. Hwang, I. K., Yi, S. S., Yoo, K. Y., Park, O. K., Yan, B., Kim, I. Y., Kim, Y. N., Song, W., Moon, S. M., Won, M. H., Seong, J. K. and Yoon, Y. S. 2010. Effects of treadmill exercise on cyclooxygenase- 2 in the hippocampus in type 2 diabetic rats: correlation with the neuroblasts. Brain Res. 1341: 84-92. [Medline] [CrossRef]

14. Iwai, M., Sato, K., Omori, N., Nagano, I., Manabe, Y., Shoji, M. and Abe, K. 2002. Three steps of neural stem cells development in gerbil dentate gyrus after transient ischemia. J. Cereb. Blood Flow Metab. 22: 411-419. [Medline] [CrossRef]

15. Kahn, S. E., Zraika, S., Utzschneider, K. M. and Hull, T. R. L. 2009. The beta cell lesion in type 2 diabetes: there has to be a primary functional abnormality. Diabetologia 52: 1003-1012. [Medline] [CrossRef]

16. Kapogiannis, D. and Mattson, M. P. 2011. Disrupted energy metabolism and neuronal circuit dysfunction in cognitive impairment and Alzheimer's disease. Lancet Neurol. 10: 187-198. [Medline] [CrossRef]

17. Kellogg, A. P. and Pop-Busui, R. 2005. Peripheral nerve dysfunction in experimental diabetes is mediated by cyclooxygenase- 2 and oxidative stress. Antioxid. Redox Signal. 7: 1521-1529. [Medline] [CrossRef]

18. Kim, B., Backus, C., Oh, S. S., Hayes, J. M. and Feldman, E. L. 2009. Increased tau phosphorylation and cleavage in mouse models of type 1 and type 2 diabetes. Endocrinology 150: 5294-5301. [Medline] [CrossRef]

19. Knapp, D. J. and Crews, F. T. 1999. Induction of cyclooxygenase-2 in brain during acutes and chronic ethanol treatment and ethanol withdrawal. Alcohol. Clin. Exp. Res. 23: 633-643. [Medline] [CrossRef]

20. Lenzen, S. 2008. The mechanisms of alloxan- and streptozotocin-induced diabetes. Diabetologia 51: 216-226. [Medline] [CrossRef]

21. Li, Z. G., Zhang, W., Grunberger, G. and Sima, A. A. F. 2002. Hippocampal neuronal apoptosis in type 1 diabetes. Brain Res. 946: 221-231. [Medline] [CrossRef] 
22. Madrigal, J. L., Moro, M. A., Lizasoain, I., Lorenzo, P., Fernandez, A. P., Rodrigo, J., Bosca, L. and Leza, J. C. 2003. Induction of cyclooxygenase-2 accounts for restraint stress-induced oxidative status in rat brain. Neuropsychopharmacology 28: 1579-1588. [Medline] [CrossRef]

23. Mirjany, M., Ho, L. and Pasinetti, G. M. 2002. Role of cyclooxygenase-2 in neuronal cell cycle activity and glutamate-mediated excitotoxicity. J. Pharmacol. Exp. Ther. 301: 494-500. [Medline] [CrossRef]

24. O'Neill, G. P. and Ford-Hutchinson, A. W. 1993. Expression of mRNA for cyclooxygenase-1 and cyclooxygenase-2 in human tissues. FEBS Lett. 330: 156-160. [Medline]

25. Paxinos, G. and Watson, C. 2007. The Rat Brain in Stereotaxic Coordinates, Elsevier Academic Press, Amsterdam.

26. Rall, J. M., Mach, S. A. and Dash, P. K. 2003. Intrahippocampal infusion of a cyclooxygenase-2 inhibitor attenuates memory acquisition in rats. Brain Res. 968: 273-276. [Medline] [CrossRef]

27. Russell, J. W., Berent-Spillson, A., Vincent, A. M., Freimann, C. L., Sullivan, K. A. and Feldman, E. L. 2008. Oxidative injury and neuropathy in diabetes and impaired glucose tolerance. $\mathrm{Neu}$ robiol. Dis. 30: 420-429. [Medline] [CrossRef]

28. Sang, N. and Chen, C. 2006. Lipid signaling and synaptic plasticity. Neuroscientist 12: 425-434. [Medline] [CrossRef]

29. Sharifzadeh, M., Tavasoli, M., Soodi, M., Mohammadi-Eraghi, S., Ghahremani, M. H. and Roghani, A. 2006. A time course analysis of cyclooxygenase-2 suggests a role in spatial memory retrieval in rats. Neurosci. Res. 54: 171-179. [Medline] [CrossRef]

30. Takagi, Y., Nozaki, K., Takahashi, J., Yodoi, J., Ishikawa, M. and Hashimoto, N. 1999. Proliferation of neuronal precursor cells in the dentate gyrus is accelerated after transient forebrain ischemia in mice. Brain Res. 831: 283-287. [Medline] [CrossRef]

31. Teather, L. A., Packard, M. G. and Bazan, N. G. 2002. Posttraining cyclooxygenase-2 (COX-2) inhibition impairs memory consolidation. Learn. Mem. 9: 41-47. [Medline] [CrossRef]

32. Thomas, J. M., Contreras, J. L., Smyth, C. A., Lobashevsky, A., Jenkins, S., Hubbard, W. J., Eckhoff, D. E., Stavrou, S., Neville, D. M. Jr. and Thomas, F. T. 2001. Successful reversal of streptozotocin-induced diabetes with stable allogeneic islet function in a preclinical model of type 1 diabetes. Diabetes 50: 1227-1236. [Medline] [CrossRef]

33. Yagita, Y., Kitagawa, K., Ohtsuki, T., Takasawa, K. I., Miyata, T., Okano, H., Hori, M. and Matsumoto, M. 2001. Neurogenesis by progenitor cells in the ischemic adult rat hippocampus. Stroke 32: 1890-1896. [Medline] [CrossRef]

34. Yamagata, K., Andreasson, K. I., Kaufmann, W. E., Barnes, C. A. and Worley, P. F. 1993. Expression of a mitogen-inducible cyclooxygenase in brain neurons: regulation by synaptic activity and glucocorticoids. Neuron 11: 371-386. [Medline] [CrossRef]

35. Yasojima, K., Schwab, C., McGeer, E. G. and McGeer, P. L. 1999. Distribution of cyclooxygenase-1 and cyclooxygenase-2 mRNAs and proteins in human brain and peripheral organs. Brain Res. 830: 226-236. [Medline] [CrossRef] 